teenth centuries, however, the main interest of philosophers was less in particular questions than in the method itself and the type of knowledge which it showed natural science to consist of. After the middle of the fourteenth century the interest concentrated still more on methodology, which caused a certain stagnation in experimental work. This is one of the reasons why six teenth and seventeenth century natural science could be felt as a completely new start instead of the fruit of a method which had flourished already some three centuries before. In a final chapter the author shows how intimately the scientific methods used by Galileo, Descartes and Newton were indeed connected with the ideas of their medieval predecessors.

The way in which all these things have been dealt with by Dr. Crombie leaves nothing to be desired. The treatment is concise, clear and complete, and it is documented with innumerable references and copious quotations from the original works. All historians of science owe a debt of sincere gratitude to him for this most valuable work.

E. J. DiJksterhuis

\section{BIRTH AND DEVELOPMENT OF SCIENTIFIC IDEAS}

Science and Industry in the Nineteenth Century By Prof. J. D. Bernal. Pp. xi +320 . (London : Routledge and Kegan Paul, Ltd., 1953.) 12s. 6d. net.

T HIS book consists of two essays dealing with the birth of scientific ideas and the complex interactions of science and technology. In the first, Prof. J. D. Bernal is concerned with the way in which scientific and technological factors affected the discovery and recognition of the laws of transformation of energy; with their bearings on our ideas of ferments and microbes as illustrated in the controversies of Liebig and Pasteur, and the interactions between organic chemistry, agriculture and medicine; with the contribution of Bessemer, Siemens and Gilchrist Thomas to the development of steel manufacture; and with the way in which the development of electricity for lighting and power production sprang from the work of Swan and Edison. The second essay is concerned with the circumstances which brought to birth in Pasteur's mind the idea of molecular asymmetry, the convergent ideas and techniques involved and the consequences which flowed from the discovery. It illustrates, and especially in a tabular summary of the origins and results of Pasteur's discovery, in which incidentally justice is done to Hankel's contribution-overlooked both by Pasteur himself and Pledge - something of the substance of Bernal's remark in his Guthrie Lecture that "Chemistry and physics are now embedded in one common theory and are in future bound to become one integral discipline". Inspired by his examination of Pasteur's unpublished notebooks, Prof. Bernal gives us a miniature in the true lineage of G. L. Lowes's "The Road to Xanadu", written with the same sympathetic insight, and it shows how fascinating and stimulating Prof. Bernal can be when his imagination and scientific discipline are firmly in the saddle.

The first essay is an able study of the relations between science and industry in the nineteenth century, to which neither Clapham's nor Cunningham's books have done anything like justice. The complexity and dynamic character of these relations are well displayed : all the factors are indicatedthe relations and interdependence of one science or technology with another; the influence of schools of teaching, of technical education, economic organization and social conditions. Prof. Bernal can see the problem as a whole and describe it clearly, and where, as in his essay on Pasteur's discovery, his scientific enthusiasm overrides his preconceived ideas, the exposition and interpretation could scarcely be better done.

In the major essay, and especially in his conclusions, Prof. Bernal cannot for long, however, maintain his objectivity. His analysis is usually fair and accurate and the irrelevances are mainly confined to footnotes, some of which could well have been omitted. In matters of doubt he is inclined to accept as proved what best accords with his own views rather than leave the matter open or present the opposing evidence. The picture is painted in tones of black and white. He does not, indeed, see scientific advance as a matter of leaps and bounds; but he regards as evil whatever hinders that advance, still more whatever delays the application of scientific knowledge to some industrial or social purpose. That science can be pursued for its own sake he finds it hard to admit. To a certain extent Bernal seems to recognize the force of Lecky's doctrine of the climate of opinion. But where opinion is unripe or unready to absorb some new idea or apply some new discovery, he is inclined to blame either the men or the institution. $\mathrm{He}$ is, in fact, intolerant of the woaknesses of human beings. That there can be a happy medium in the lag between scientific advance and technological discovery scarcely occurs to him. And if Lord Stamp's doctrine of a science of technological adjustment has scarcely been fully formulated, Prof. Bernal might reflect that in it there is at least the recognition that the pace of technical change may put severe and undesirable strain on the human element affected. That factor also has its bearing on the development of inventions, and it is not necessary to attribute all reluctance to develop new ideas to malevolence and incompetence. It is unreasonable to expect a commercial or industrial firm to be dominated by philanthropic motives, and on the point of prescience or neglect it is well to remember Guizot's dictum : "Il n'y a pas tant de prémeditation dans les affaires humaines, et leur cours est plus naturel que ne le croit le vulgaire".

R. Brightman

\section{BIOCHEMISTRY AND PHYSIOLOGY OF NUTRITION}

\section{Biochemistry and Physiology of Nutrition}

Vol. 1. Edited by Geoffrey H. Bourne and George W. Kidder. Pp. xiii +569. (New York : Academic Press, Inc. ; London: Academic Books, Ltd., 1953.) 13 dollars.

DROGRESS has been such that for research workers and more advanced students there has been a general need for compilations of detailed reviews of current knowledge by experts in a particular subject, and the publication of these in a series of now well-known annual reviews has met a 